\title{
EDITORIAL
}

\section{In This Issue: Cohort Studies}

\author{
Kurt C. Stange, $M D, P b D$, Editor
}

Ann Fam Med 2008;6:482-483. DOI: 10.1370/afm.924.

$\mathrm{T}$ his issue contains 6 studies based on a follow-up of cohorts of patients, ${ }^{1-6} 3$ studies from networks of practices, ${ }^{4,5,7}$ and 4 studies from national population samples. ${ }^{1,2,8}$ There is some overlap in these categories, which represent strong methods for the types of questions asked. Qualitative methods ${ }^{9}$ and an analysis of administrative data ${ }^{10}$ showcase other methods well suited to their research question.

The impact of ethnic and racial inequalities in hypertension is starkly portrayed by 2 studies, ${ }^{1,7}$ and commentaries from distinguished editorialists ${ }^{11,12}$ amplify and elucidate this important topic.

This issue's Annals Journal Club featured study follows the course of a cohort of patients with fatigue identified in a network of 147 primary care practices. The discovery of comorbid symptoms and 4 different patterns of outcomes over time are useful for discussing prognosis and planning follow-up with patients.

Another prospective study develops a model to predict new-onset of depressive symptoms and depression in adolescents, allowing high-risk adolescents to be identified. ${ }^{2}$

A further follow-up study finds that $3 \%$ of visits by women are for breast symptoms, and 3\% of these women subsequently have breast cancer diagnosed. ${ }^{5}$ This risk is increased by the presence of a mass.

A cost-effectiveness analysis of clinical trial data evaluates an automated telephone self-management support and nursing care intervention of safety net practice patients with diabetes. ${ }^{3}$

A study of representation of family medicine in US National Institutes of Health grants and scientific review committees finds low levels. ${ }^{10}$

A qualitative study identifies factors related to nondisclosure of health information by Latina patients. ${ }^{9}$ The identified factors are a reminder to attend to human and humanist approaches to enable the most important diagnostic test - the medical history - and a vital therapeutic intercession - the clinician-patient relationship.

In a study by Asplund and colleagues, a maternal body mass index increase of $25 \%$ and greater is associated with a shockingly high incidence of neonatal macrosomia. ${ }^{6}$
A new, empirically derived clinical tool to assess the likelihood of fasting glucose impairment ${ }^{8}$ may be useful in helping to focus resources for diet, activity, and possibly pharmacological interventions.

Please share your insights on these articles and your experience with the important topics they bring up by joining the Annals online discussion at http://www. AnnFamMed.org.

\section{A NEW ANNALS EDITOR}

We are delighted to announce that the Annals has a new associate editor. Patricia A. Carney, $\mathrm{PhD}$, is currently Professor of Family Medicine and of Public Health and Preventive Medicine and Associate Director for Population Studies at the Cancer Institute at Oregon Health Sciences University. Dr Carney received her doctoral degree from the University of Washington in Seattle, Washington. She obtained bachelor's and master's degrees and experience in nursing before launching a distinguished research career. Her doctoral training includes 2 specialty areas: health services research (public health and community medicine) and educational psychology. She leads a number of studies that have been funded by the National Cancer Institute and the Agency for Research in Healthcare Quality. She is widely recognized as a strong methodologist, an expert in breast cancer screening research and educational research, and a leader in the use of standardized patients in clinical research and medical education. We look forward to her wisdom in the editing process.

\footnotetext{
References

1. Fiscella K, Holt K. Racial disparity in hypertension control: tallying the death toll. Ann Fam Med. 2008;6(6):497-502.

2. Van Voorhees BW, Paunesku D, Gollan J, Kuwabara S, Reinecke M, Basu A. Predicting future risk of depressive episode in adolescents: the Chicago Adolescent Depression Risk Assessment (CADRA). Ann Fam Med. 2008;6(6):503-511

3. Handley MA, Shumway M, Schillinger D. Cost-effectiveness of automated telephone self-management support with nurse care management among patients with diabetes. Ann Fam Med. 2008;6(6):512-518.
} 
4. Nijrolder I, van der Windt D, van der Horst H. Prognosis of fatigue and functioning in primary care: a 1-year follow-up study. Ann Fam Med. 2008;6(6):519-527.

5. Eberl MM, Phillips RL Jr, Lamberts H, Okkes I, Mahoney MC. Characterizing breast symptoms in family practice. Ann Fam Med. 2008;6(6):528-533

6. Asplund C, Seehusen DA, Callahan T, Olsen C. Percentage change in antenatal body mass index as a predictor of neonatal macrosomia. Ann Fam Med. 2008;6(6):550-554.

7. Millett C, Gray J, Bottle A, Majeed A. Ethnic disparities in blood pressure management in patients with hypertension after the introduction of pay for performance. Ann Fam Med. 2008;6(6):490-496.

8. Koopman RJ, Mainous AG III, Everett CJ, Carter R. Tool to assess likelihood of fasting glucose impairment (TAG-IT). Ann Fam Med. 2008;6(6):555-561.
9. Julliard K, Vivar J, Delgado C, Cruz E, Bellask J, Sabers H. What Latina patients don't tell their doctors: a qualitative study. Ann Fam Med. 2008;6(6):543-549.

10. Lucan SC, Phillips R, Bazemore AW. Off the roadmap? Family medicine's grant funding and committee representation at NIH. Ann Fam Med. 2008;6(6):534-542.

11. Cené CW, Cooper LA. Death toll from uncontrolled blood pressure in ethnic populations: universal access and quality improvement may not be enough. Ann Fam Med. 2008;6(6):486-489.

12. Satcher D. Examining racial and ethnic disparities in health and hypertension control. Ann Fam Med. 2008;6(6):483-485.

\title{
EDITORIAL
}

\section{Examining Racial and Ethnic Disparities in Health and Hypertension Control}

\author{
David Satcher, MD, $P b D$ \\ Morehouse School of Medicine, Atlanta, Georgia \\ Ann Fam Med 2008;6:483-485. DOI: 10.1370/afm.927.
}

A national strategy for improving the health of the American people has been defined for each decade since 1980. ${ }^{1}$ When Healthy People $2010^{2}$ was released in 2000, there were 2 overarching goals. The first goal dealt with our need to focus more attention on improving quality of life, not just years of life lived. The second goal was the elimination of disparities in health among different racial and ethnic groups. Whereas reducing disparities in health has been part of Healthy People 2010 for some years, targeting the elimination of disparities in health brought the kind of attention and planning to disparities in health that had not been seen before. In 2002 the Institute of Medicine (IOM), at the request of the government, released

Conflicts of interest: none reported

\section{CORRESPONDING ADDRESS}

David Satcher, MD, PhD

Satcher Health Leadership Institute

Morehouse School of Medicine

720 Westview Dr, SW, NCPC 238

Atlanta, GA 30310

dsatcher@msm.edu the report Unequal Treatment: Confronting Racial and Etbnic Disparities in Healthcare. ${ }^{3}$ It was a very thorough and indepth examination of the issue of disparities in health care and is considered by many to be the guidebook.

To better monitor progress toward the 2 goals, the government asked the Agency for Healthcare Research and Quality (AHRQ) to monitor and generate annual reports addressing these issues. Although the reviews have been mixed, there are indications that we are making progress in closing some of the gaps in quality of care. ${ }^{4}$

In 2005, my colleagues and I published in Health Affairs the results of a study in which we examined mortality ratios of blacks and whites from 1960 to $2000_{i}$ we found very little change in the ratios during that period. ${ }^{5}$ In addition, we showed that had we eliminated disparities in health in the last century; in the year 2000 alone there would have been 83,500 fewer deaths among blacks in America. Although mortality is not the only measure of disparities, it is certainly the most definitive and is a measure of health outcomes that are determined not only by health care but also health behavior, environment, and biological differences in response to medications. Hypertension is a 